\title{
John Wyclif și ordinele religioase călugărești
}

\author{
George-Gabriel NIȘCOVEANU*
}

Abstract. The reform draft of the English theologian John Wyclif included in the late fourteenth century the dissolution of the monastic religious orders from the Church. The main reason for this new approach was the discrepancy between the monks'way of life and the ideal of the monastic life spent in poverty and selfless as the one of our Savior Jesus Christ. Although he was at first a supporter of the monastic ideal, especially of the Franciscans, one can see that at the end of his life Wyclif will trigger an unprecedented attack against the religious orders. Wyclif did not stop there, but he organized his own group, the so-called "poor priests", which led a life of poverty, going barefoot throughout the kingdom of England, preaching the gospel and the new doctrines of their master. This study focuses on all those aspects following the analysis of the key points of the relation between John Wyclif and the religious orders.

Key words: John Wyclif, England, religious orders, mendicants, poor priests.

\footnotetext{
${ }^{*} \mathrm{PhD}$ candidate in Church History, Faculty of Orthodox Theology, Bucharest University, Romania.
} 


\section{John Wyclif - director la Colegiul Canterbury}

Contextul politic și social din Europa și din Anglia secolului al XIV-lea a fost unul cu totul special. În Anglia lunga domnie a regelui Edward al III-lea (1327-1377) și intrarea acestuia într-o lungă și anevoioasă campanie de cucerire a Franței (cunoscută mai apoi în istorie ca Războiul de 100 de ani 1337-1453) punea la grea încercare economia regatului; pretențiile crescânde ale Papalității, al cărei scaun se afla la Avignon în Franța și mai târziu Schisma Apuseană din 1378; epidemia de ciumă care a ucis mai mult de o treime din populația Europei; sunt doar câteva dintre aspectele importante ale cadrului în care s-a desfășurat activitatea teologului și reformatorului englez John Wyclif, care cu aproape 150 de ani înainte de Martin Luther, Huldrych Zwingli sau Jean Calvin schițează cele mai importante idei care vor sta la baza Reformei.

Asupra primei părți a vieții lui John Wyclif planează încă o serie de incertitudini. Deși există foarte multe izvoare și documente referitoare la ultima parte a vieții lui, cele referitoare la primele patru decenii sunt aproape inexistente. Nu există nicio mărturie clară în legătură cu anul sau locul nașterii lui Wyclif. Dificultatea procesului de stabilire a datei nașterii este dată și de existența în epocă a mai multor persoane cu acest nume (pot fi identificate patru persoane diferite ${ }^{2}$ ), neputându-se face o afirmație definitivă în acest sens.

Prima dată atestată cu siguranță este anul $1356^{3}$. În primăvara acelui an Wyclif devine licențiat în litere și filosofie ${ }^{4}$ la Oxford. În anul 1360 Wyclif obține titlul de Master în Litere și Filosofie, lucru confirmat de un document în care este scris: „Luni, după sărbătoarea Înălțării

\footnotetext{
${ }^{2}$ Andrew Larsen, John Wyclif, în I. C. Levy (ed.), „Brill's Companions to the Christian Tradition", vol. IV, Boston, Leiden Brill, 2006, p. 12, nota 38.

${ }^{3} \mathrm{O}$ dată încă destul de controversată, existând numeroase ipoteze greu de susținut în ceea ce privește perioada în care John Wyclif a studiat la Oxford. ${ }^{4}$ J. A. Robson, Wyclif and the Oxford Schools, Cambridge, Cambridge University Press, 1961, p. 10, nota 5.
} 
Domnului, John Wyclif, master al scolasticilor..."5.

Este posibil ca John Wyclif să fi fost înaintat în treapta de preot înainte de 1361, când pe 14 mai este instalat ca preot paroh la Fillingham - Lincolnshire, fiind hirotonit de John Thoresby ${ }^{6}$. Pe 29 august 1363, ca urmare a unei cereri depuse de Wyclif, episcopul Buckingham de Lincoln îi acordă acestuia o autorizație de nonrezidență pentru a-și continua studiile teologice la Oxford. Drept urmare, în toamna aceluiași an, John Wyclif își începe pregătirea teologică, care în secolul al XIV-lea dura 7 ani. În martie 1369 obține licența în teologie și doctoratul la sfârșitul anului 1372.

În 1361 arhiepiscopul Simon Islip de Canterbury a fondat Colegiul Canterbury la Oxford (atât pentru monahi - în special benedictini, cât și pentru clerici) și 1-a numit pe Wyclif director în decembrie $1365^{7}$. Apare problema identificării acestui Wyclif cu reformatorul de mai târziu, în epocă existând mai multe persoane cu acest nume. Walter Shirley consideră că este vorba despre John Wyclyve, paroh în Mayfield - Sussex ${ }^{8}$, lucru confirmat și de Reginald Lane Poole care găsește o conexiune între arhiepiscopul Islip și acesta din urmă. Se pare că fiind paralizat în ultimii ani de viață, Islip și-a petrecut timpul chiar în această localitate ${ }^{9}$. Există însă două contraargumente solide. Primul este consemnat în Chronicon Angliae, o scriere contemporană cu evenimentele, care vorbește despre deposedarea pe bună dreptate a lui John Wyclif de anumite beneficii

\footnotetext{
${ }^{5}$ Herbert B. Workman, John Wyclif - A Study of the English Medieval Church, vol. I, Oxford, Clarendon Press, 1926, p. 78.

${ }^{6}$ Ibidem, p. 151.

${ }^{7}$ Stephen E. Lahey, John Wyclif, New York, Oxford University Press, 2009, p. 6.

${ }^{8}$ Walter Shirley, Note on the two John Wyclifs, în „Fasciculi Zizaniorum Magistri Johannis Wyclif cum Tritico”, Longman, Brown, Green, Longmans, and Roberts, Londra, 1858, p. 507.

${ }^{9}$ Reginald Lane Poole, Wycliffe and Movements for Reform, Longmans, Green \& Co., Londra, 1889, p. 68, nota 1.
} 
deținute la Oxford de către arhiepiscopul de Canterbury ${ }^{10}$. Al doilea este chiar o relatare a lui John Wyclif, în care acesta face referire la cazul de la Colegiul Canterbury, acuzându-l pe Simon Langham (îl numește pe acesta Anti-Simon în comparație cu Simon Islip) ${ }^{11}$, o relatare care conform lui Lechler are valoarea unui „familiarum exemplum" 12 .

După numai un an Islip moare (26 aprilie 1366), urmându-i în scaunul de arhiepiscop Simon Langham. Acesta a vrut să-l îndepărteze pe Wyclif din funcția de director, în special datorită tensiunilor existente provocate de nemulțumirea monahilor, dar Wyclif a apelat la papa Urban al V-lea, ce avea scaunul la Avignon. După 4 ani, pe 11 mai 1370, papa ia hotărârea de a-l înlătura pe Wyclif, hotărâre confirmată și de rege printrun act emis la 8 aprilie 1372. Andrew Larsen este de părere că Islip a vrut la conducere un pure clerici saecularis, iar Langham a greșit schimbând această hotărâre ${ }^{13}$. Se spune că fiind un simpatizant al franciscanilor, cât timp a fost director la Canterbury, umbla doar într-o mantie lungă cafenie și desculț. Această afirmație este făcută de Workman ${ }^{14}$ pe baza unui text din Collectanea ${ }^{15}$. Pe seama acestui conflict este pusă animozitatea de mai târziu a lui Wyclif față de ordinele călugărești.

Gruparea anticlericală a văzut în John Wyclif persoana potrivită pentru a sprijini condamnarea averii bisericești, acesta fiind angajat ca peculiaris regis clericus - cleric aflat în slujba regelui ${ }^{16}$. În iulie 1376

${ }_{10}$ Thomas Walsingham, Chronicon Angliae, editată de Edward Maunde Thompson, Longman \& Co., Londra, 1874, p. 115.

${ }^{11}$ Iohannis Wyclif, Tractatus De Ecclesia, editată de Iohann Loserth, Trübner \& Co., Londra, 1886, p. 371.

${ }^{12}$ Gotthard Victor Lechler, John Wiclif and his English Precursors, traducere în limba engleză și note de Peter Lorimer, Kegan Paul, Trench, \& Co., Londra, 1881, p. 131, nota 16.

${ }^{13}$ A. Larsen, art. cit., p. 15.

${ }^{14}$ H. B. Workman, op. cit., p. 187.

${ }^{15}$ John Leland, Collectanea, vol. III, Londra, Gul. et Jo. Richardson, 1770, p. 409.

${ }^{16}$ R. L. Poole, op. cit., pp. 65-66. 
Wyclif a făcut parte dintr-o comisie regală ce s-a întâlnit la Bruges cu reprezentanții papali pentru a discuta problema plății tributului. Când John Gaunt a propus guvernului confiscarea averilor bisericești, 1-a chemat pe Wyclif să apere propunerea într-o serie de predici ținute în Londra (1376). Wyclif a predicat împotriva conducerii clericale a Bisericii, criticând în special decăderea vieții morale a preoților, dar și împotriva ordinelor de călugări cerșetori ${ }^{17}$.

Pe 27 martie 1378 papa Grigorie al XI-lea moare și câteva luni mai târziu are loc Schisma Papală, ce a împărțit și a slăbit autoritatea papalității. Ca reacție la acest eveniment Wyclif scrie tratatul Schisma Papae. El prezintă întregul sistem papal ca anticreștin. Papa era Antihristul, iar decretele promulgate erau legile inamicului lui Hristos. Ofensiva lui Wyclif continuă și în alte tratate, în care atacă ordinele călugărești, doctrina meritelor prisositoare și a indulgențelor, cere judecarea clericilor de către curțile seculare, susține că oamenii ar trebui să creadă în papă doar în măsura în care acesta urmează lui Hristos.

\section{Atacul împotriva ordinelor religioase călugărești}

În primă fază, Wyclif a avut în ordinele de călugări cerșetori un aliat de bază în demersul său prin care ataca posesiunile monastice. Deși în februarie 1377 John Gaunt a reușit să convoace călugări din fiecare din cele patru ordine pentru a-l apăra pe Wyclif la St. Paul, din momentul în care acesta începe să susțină desființarea ordinelor de călugări, își pierde aliații ${ }^{18}$.

\footnotetext{
${ }^{17}$ Monahii cerșetori marchează o etapă interesantă în evoluția ecclesială. Ei aveau ca particularitate evanghelizarea. Ideea lor era de a merge între semenii lor, să caute și să îi salveze pe cei pierduți, dar pe parcurs au devenit foarte bogați. Au crescut ca număr și ca putere, au dobândit proprietăți foarte mari și au ocupat posturi de conducere în universități. Cu cât a cercetat mai mult cuvântul lui Dumnezeu, cu atât mai mult a văzut discrepanța dintre viața călugărilor și cea a lui Hristos și a apostolilor.

${ }^{18}$ L. J. Daly, The Political Theory of John Wyclif, Chicago, Loyola University Press, 1962, p. 92.
} 
Existau cinci acuzații de bază împotriva călugărilor: ipocrizia, numărul lor excesiv, abuzul împotriva votului sărăciei, predicarea spre satisfacerea mulțimilor (în 1300 papa Benedict VIII dă bula Super cathedram prin care acorda călugărilor dreptul de a predica în bisericile și locurile publice, cu condiția ca la ora respectivă să nu predice un prelat loca ${ }^{19}$ ), furtul drepturilor seculare ale episcopilor, preoților și laicilor ${ }^{20}$. Wyclif deplânge faptul că ei jefuiesc poporul, își construiesc case somptuoase pe pământurile cele mai fertile și ofereau adăpost doar oamenilor bogați și femeilor. Îi acuză de relații sexuale cu femei căsătorite, cu văduve sau cu călugărițe, lucru recunoscut și de unii din reprezentanții ordinelor călugărești (de exemplu franciscanul John Brugman ${ }^{21}$. Toți se făceau vinovați de schismă și idolatrie pentru că 1-au respins pe Hristos în favoarea patronilor lor religioși: Augustin, Benedict, Francisc și Dominic. Wyclif va reuni cele patru ordine călugărești sub o singură denumire - acronimul CAIM, care 1-a ucis pe fratele său Abel: Carmeliții, Augustinii, Iacobiții (Dominicanii) și Minoriții (Franciscanii), sau le va asemăna cu cele patru fiare pe care Daniel le-a văzut ieșind din mare 22 . Wyclif a fost împotriva a tot ceea ce numește „religie privată” adică orice pretenție de drepturi și privilegii speciale a unor grupuri de creștini. În ultima parte a vieții a ajuns să privească ordinele de călugări cerșetori înființate de papa Inocențiu al III-lea mai rele ca toți demonii, parte a unui mare plan de a introduce autoritatea papală în fiecare aspect al vieții religioase.

De aceea, în timp ce Fitz Ralph apelează la papa Clement al VI-lea pentru a-i priva pe călugării cerșetori de privilegiile dobândite pe nedrept, Wyclif și-a îndreptat privirea către puterea laică, guvernul

${ }^{19}$ Ian Cristopher Levy, Wyclif and the Christian Life, în: I. C. Levy (ed.), „Brill's Companions to the Christian Tradition", vol. IV, Boston, Leiden Brill, 2006, p. 305. ${ }^{20} \mathrm{O}$ listă mai cuprinzătoare este oferită de Thomas Renna, Wyclif's Attacks on the Monks, în „From Ockham to Wyclif”, ed. A. Hudson and M. Wilks, Blackwell, Oxford, 1987, p. 268.

${ }^{21}$ I. C. Levy, art. cit., p. 299.

${ }^{22}$ Ibidem, 301. 
englez urmând să devină instrumentul Reformei ${ }^{23}$.

\section{„Preoții săraci” sau ,secta Wyclif”}

$\mathrm{Cu}$ toate acestea, Wyclif nu a ezitat să-și formeze propriul ordin de predicatori intineranți; parte a agitației de la Oxford, ce a stat în legătură cu Revolta țăranilor din 1381 și cu nașterea mișcării lollarde, fiind și activitatea așa numiților ,preoți-săraci”24. Wyclif se plângea în Trialogus că „,preoții săraci” sunt urmăriți în diocezele Londra și Lincoln $^{25}$. Tot acesta scria în ultimii ani ai vieții sale că Hristos, ai cărui apostoli nu au avut diplome, nu vrea absolvenți erudiți, promovați pentru venituri importante, ci oameni simpli care să urmeze școala lui Hristos și doctrina Lui. Absolvirea duce la o superficialitate în predică, înlocuirea ei cu poeme și fabule care nu se fundamentează pe Scripturăa ${ }^{26}$. Reformatorul englez susținea în iunie 1383 că John Gaunt îi proteja pe „,preoții săraci” și că în consecință ducele fusese victima unui complot pus la cale de călugării cerșetori ${ }^{27}$. În principiu se cunoaște din lucrările lui Wyclif că acesta a intenționat ca mesajul lui să fie propovăduit de o armată de ,preoți săraci” ${ }^{28}$. Knighton afirmă că lollarzii erau o sectă, un nou ordin religios, ce se îmbrăcau în haine dintr-o stofă roșiatică spre a arăta lumii simplitatea inimii lor. Thomas Walsingham susține o idee asemănătoare: pentru a amăgi oamenii simpli s-au asociat cu ordinele

${ }^{23}$ K. B. McFarlane, John Wycliffe and the Beginnings of English Nonconformity, Pelican Books, 1972, p. 49.

${ }^{24}$ E. P. Cheyney, The Recantations of the Early Lollards, în „The American Historical Review”, vol. IV, Londra, The Macmillan Company, 1899, p. 424.

${ }^{25}$ Johannis Wiclif, Trialogus, editată de Gotthard Lechler, Oxford, Clarendon Press, 1869, p. 379.

${ }^{26}$ Johannis Wyclif, Opera Minora, editată de dr. Johann Loserth, C. K. Paul \& Co., Londra, 1913, p. 245.

${ }^{27}$ Rudolf Buddensieg (ed.), John Wyclif's Polemical Works in Latin, vol. I, Londra, Trübner \& Co., 1883, p. 95.

${ }^{28}$ Michael Wilks, Wyclif: Political Ideas and Practice, editată de Anne Hudson, Oxford, Oxbow Book, 2000, pp. 73-75, 101-103. 
călugărilor cerșetori, punând la loc de cinste sărăcia ${ }^{29}$.

Lechler consideră că probabil începând încă din 1378, mulți predicatori neautorizați de Biserică, sub îndrumarea directă a lui Wyclif și a altor oameni de la Oxford, străbăteau țara predicând în locuri publice, având ca sediu Lutterworth ${ }^{30}$ sau, dată fiind aria de răspândire a primelor comunități lollarde în partea esticăa Oxfordshire, mișcarea putea fi condusă din Lugershall, parohie deținută de Wyclif între 1368 și 1374, iar mai apoi de la Oxford, ipoteză susținută de Dr. Lorimer ${ }^{31}$. Workman consideră că Wyclif i-ar fi organizat pe acești preoți intineranți după metodele instituite de Sf. Francisc de Assisi pentru franciscani, propunând ca posibilă dată la care au luat ființă anul 137732. Shannon McSheffrey a argumentat că pe durata întregii istorii lollarde aceștia au format un grup social distinct de indivizi, definiți de respingerea conștientă a autorității Bisericii Catolice ${ }^{33}$.

Cannon, într-un articol din 1900, îl prezintă pe Wyclif ca responsabil cel puțin pentru grupul inițial de ,preoți săraci”’34. Cannon consideră că Wyclif a trimis preoți săraci - sacerdotes simplices (acest cuvânt poate însă desemna în unele contexte și călugări franciscani ce-și părăsiseră ordinul monahal) - să propovăduiască încă din 1376-1377. Activitatea acestora poate fi delimitată pentru că tratatele wycliffite folosesc un vocabular ușor identificabil. Mergeau desculți, îmbrăcați într-un veșmânt din lână roșiatică.

Istoricii de mai târziu au pus sub semnul întrebării concluziile la care ajunsese acesta și sursele pe care se baza în argumentarea lui. Astfel Gordon Leff afirmă că nu este absolut nicio dovadă în scrierile

\footnotetext{
${ }^{29}$ Th. Walshingham, op. cit., p. 116.

${ }^{30}$ G. V. Lechler, op. cit., 1884, p. 367.

${ }^{31}$ Ibidem, p. 201, nota 2.

${ }^{32}$ H. B. Workman, op. cit., p. 201.

${ }^{33}$ Shannon McSheffrey, Heresy, Orthodoxy and English Vernacular Religion, 1480-1525, în „Past \& Present”, nr. 186/2005, pp. 47-80.

${ }^{34}$ A se vedea: H. L. Cannon, The Poor Priests; a Study in the rise of English Lollardry, în „Annual Report of the American Historical Association for 1899”, vol. I, Washington, Government Printing Office, 1900, pp. 451-482.
} 
lui Wyclif, mai ales în predicile lui, că acesta ar fi organizat un corp de predicatori ${ }^{35}$. De asemeni și Margaret Aston are dubii în privința activității lui John Wyclif, cea de organizator al mișcării lollarde ${ }^{36}$. McFarlane afirmă că într-adevăr lipsa dovezilor care 1-ar conecta pe Wyclif după retragerea sa la Lutterworth cu grupul de lollarzi din Leicester pune sub semnul întrebării faptul că mișcarea lollardă ar fi fost inspirată de Wyclif, dar doctrinele pe care le au în comun sunt prea multe pentru a permite vreun fel de scepticism, și cea mai bună explicație este că mișcarea a fost inspirată de Wyclif dar nu condusă de acesta ${ }^{37}$. Evans la rândul său scrie că nu există nicio dovadă clară că Wyclif încuraja și ghida un corp de predicatori, care nu aveau pregătire teologică (?) și ar fi avut nevoie de rezumate scrise de Wyclif în limba latină care să le fie de folos, dar niciuna din ultimele lucrări ale lui Wyclif nu poate fi considerată manual ${ }^{38}$.

Contemporanii însă nu au avut niciun dubiu în a-l asocia pe Wyclif cu mișcarea lollardă. Knighton scria că William Swinderby s-a asociat cu William Smith din Leicester și cu alții de secta Wycliff9.

\section{Bibliografie}

1. Aston, Margaret, The Impeachment of Bishop Despenser, în „Buletin of the Institute os Historical Research", vol. 38, 1967.

2. Buddensieg, Rudolf (ed.), John Wyclif's Polemical Works in Latin, vol. I, Londra, Trübner \& Co., 1883.

\footnotetext{
${ }^{35}$ Gordon Leff, Heresy in Later Middle Ages, Manchester, Manchester University Press, 1967, p. 524, nota 5.

${ }^{36}$ Margaret Aston, The Impeachment of Bishop Despenser, în „Buletin of the Institute os Historical Research", vol. 38, 1967, pp. 269-270.

${ }^{37}$ K. B. McFarlane, Lancastrian Kings and Lollard Knights, Oxford, Oxford University Press, 1972, p. 140.

${ }^{38}$ Gillian Evans, John Wyclif: Myth and Reality, IL: IVP Academic, Downer's Grove, 2006, p. 205.

${ }^{39}$ Henrici Knighton, Chronicon, editată de Joseph Rawson Lumby, vol. II, Londra, Royal Society, Kraus Reprint LTD, 1965, pp. 190-191.
} 
3. Cannon, H. L., The Poor Priests; a Study in the rise of English Lollardry, în „Annual Report of the American Historical Association for 1899", vol. I, Washington, Government Printing Office, 1900.

4. Cheyney, E. P., The Recantations of the Early Lollards, în „The American Historical Review", vol. IV, Londra, The Macmillan Company, 1899.

5. Daly, L. J., The Political Theory of John Wyclif, Chicago, Loyola University Press, 1962.

6. Evans, Gillian, John Wyclif: Myth and Reality, IL: IVP Academic, Downer's Grove, 2006.

7. Knighton, Henrici, Chronicon, editată de Joseph Rawson Lumby, vol. II, Londra, Royal Society, Kraus Reprint LTD, 1965.

8. Lahey, Stephen E., John Wyclif, New York, Oxford University Press, 2009.

9. Larsen, Andrew, John Wyclif, în: I. C. Levy (ed.), „Brill's Companions to the Christian Tradition",vol. IV, Boston, Leiden Brill, 2006.

10. Lechler, Gotthard Victor, John Wiclif and his English Precursors, traducere în limba engleză și note de Peter Lorimer, Kegan Paul, Trench, \& Co., Londra, 1881.

11. Leff, Gordon, Heresy in Later Middle Ages, Manchester, Manchester University Press, 1967.

12. Leland, John, Collectanea, vol. III, Londra, Gul. et Jo. Richardson, 1770.

13. Levy, Ian Cristopher, Wyclif and the Christian Life, în: I. C. Levy (ed.), „Brill's Companions to the Christian Tradition”, vol. IV, Boston, Leiden Brill, 2006.

14. McFarlane, K. B., John Wycliffe and the Beginnings of English Nonconformity, Pelican Books, 1972.

15. McFarlane, K. B., Lancastrian Kings and Lollard Knights, Oxford, Oxford University Press, 1972.

16. McSheffrey, Shannon, Heresy, Orthodoxy and English Vernacular Religion, 1480-1525, în „Past \& Present”, nr. 186/2005.

17. Poole, Reginald Lane, Wycliffe and Movements for Reform, Londra, Longmans, Green \& Co., 1889.

18. Renna, Thomas, Wyclif's Attacks on the Monks, în „From Ockham to Wyclif", ed. A. Hudson and M. Wilks, Blackwell, Oxford, 1987.

19. Robson, J. A., Wyclif and the Oxford Schools, Cambridge, Cambridge University Press, 1961. 
20. Shirley, Walter, Note on the two John Wyclifs, în „Fasciculi Zizaniorum Magistri Johannis Wyclif cum Tritico", Longman, Brown, Green, Longmans, and Roberts, Londra, 1858.

21. Walsingham, Thomas, Chronicon Angliae, editată de Edward Maunde Thompson, Longman \& Co., Londra, 1874.

22. Wiclif, Johannis, Trialogus, editată de Gotthard Lechler, Oxford, Clarendon Press, 1869.

23. Wilks, Michael, Wyclif: Political Ideas and Practice, editată de Anne Hudson, Oxford, Oxbow Book, 2000.

24. Workman, Herbert B., John Wyclif-A Study of the English Medieval Church, vol. I, Oxford, Clarendon Press, 1926.

25. Wyclif, Iohannis, Tractatus De Ecclesia, editată de Iohann Loserth, Trübner \& Co., Londra, 1886.

26. Wyclif, Johannis, Opera Minora, editată de dr. Johann Loserth, C. K. Paul \& Co., Londra, 1913. 
